\title{
GH improves growth and clinical status in children with cystic fibrosis - a review of published studies
}

\author{
Dana S Hardin \\ University of Texas Southwestern Medical School, 5323 Harry Hines Boulevard G2.220, Dallas, TX 75390-9063, USA \\ (Correspondence should be addressed to D Hardin; Email: dana.hardin@utsouthwestern.edu)
}

\begin{abstract}
Children with cystic fibrosis (CF) have problems with poor linear growth and inadequate weight gain. Nutritional augmentation has been the mainstay of therapy for improving both weight and height in CF; however, inadequate growth continues to be a problem. Furthermore, protein catabolism has been documented even in non-acutely ill adults and children with $\mathrm{CF}$, and could adversely affect longitudinal growth. Human recombinant $\mathrm{GH}$ has positive effects on nitrogen balance, and multiple studies have demonstrated improved height and weight in children treated with GH. The purpose of this article is to summarize studies evaluating $\mathrm{GH}$ use in children with $\mathrm{CF}$.

All published studies of GH use in children with CF have demonstrated significant improvement in height velocity and height $\mathrm{Z}$ score. All studies but one, in which subjects were treated only three times per week with $\mathrm{GH}$, have demonstrated improvement in weight as reported by weight velocity and/or weight $\mathrm{Z}$ score, and one trial has demonstrated a substantial improvement when GH was used to augment nutritional therapy. Several reports suggest that GH treatment results in improved forced vital capacity, and multiple studies have found improved clinical status as measured by decreased hospitalizations and courses of intravenous antibiotics. Furthermore studies to date also suggest that GH results in improvement in exercise tolerance and bone accumulation. To date significant side effects, including glucose intolerance, have not been reported. Thus mounting evidence suggests that human recombinant GH provides safe and effective therapy in children with $\mathrm{CF}$.
\end{abstract}

European Journal of Endocrinology 151 S81-S85

\section{Poor growth is common in cystic fibrosis (CF)}

Children with CF have difficulty gaining weight and struggle to attain normal linear growth. The most recent North American CF Foundation Annual Report (1) documented that $26 \%$ of $\mathrm{CF}$ children are below the 10th percentile for weight and $29 \%$ are below the 10th percentile for height. Unfortunately, the growth deficit is not corrected during puberty. Previous studies $(2,3)$ have documented that patients with $\mathrm{CF}$ have delay in attainment of pubertal maturation. These same studies also document blunting of maximal growth velocity once puberty ensues. Adults with CF have lower than average final adult heights. Adult males with CF reach an average height of $172.8 \mathrm{~cm}$ (36th percentile) and females $160.4 \mathrm{~cm}$ (38th percentile) (North American annual CF registry, unpublished data). Furthermore, $34 \%$ of $\mathrm{CF}$ adults were below the 85th percentile of ideal body weight (1).

Multiple studies have demonstrated the association between poor weight gain and worsened clinical status $(4,5)$ and much emphasis has been placed on improving nutrition in these patients. However, improvement of longitudinal growth may be important independently of the issue of improved weight gain. Two independent groups have documented an association between poor linear growth and later worsened pulmonary function $(6,7)$. These groups have hypothesized that better longitudinal growth allows more lung mass resulting in better lung function. Improvement of linear growth has typically focused on improvement of nutritional intake. However, studies have suggested that stunted linear growth in children with CF can occur independently of poor nutritional intake $(8-10)$. Our group reviewed the relationship between weight gain and linear growth by reviewing the Epidemiologic Study of CF database (ESCF, Genentech, Inc., South San Francisco, CA, USA) and found poor correlation between the two (11). Thus, nutritional supplementation alone may not be the best means for improving short stature in CF. Human recombinant growth hormone $(\mathrm{GH})$ stimulates accrual of linear height, and has been used to improve weight gain in chronic illness (12-14). Multiple studies have documented its efficacy in children with CF.

\section{Published studies of GH treatment in CF children}

\section{Anthropometric data}

Early case reports of $\mathrm{GH}$ use in CF reported improved height; however, weight was not evaluated (15). 
A retrospective analysis (16) of $24 \mathrm{CF}$ patients treated with daily GH and whose data were maintained by the National Cooperative Growth Study (NCGS), demonstrated increased height velocity, height $\mathrm{Z}$ scores and weight for height standard deviation. Two patients, who were pubertal, developed glucose intolerance; however, there was no indication of prescreening for diabetes prior to initiation of GH treatment.

Several non-randomized prospective trials have been conducted. Sackey et al. (17) reported improved height velocity, height $\mathrm{Z}$ score and weight velocity in seven prepubertal children treated daily with GH. Huseman et al. (18) conducted a study of nine children treated with GH three times per week and reported improved height velocity and height $\mathrm{Z}$ scores; however, weight velocity did not statistically improve; weight Z score was not reported. Our group (19) studied nine prepubertal children treated daily with $\mathrm{GH}$ and found improved height velocity, height $\mathrm{Z}$ score, weight velocity and weight $\mathrm{Z}$ score. Skin-fold thickness decreased despite increased body weight, suggesting improved lean tissue mass (LTM). Alemzadeh et al. (20) studied GH effects in very young children (6 months-5.2 years) with $\mathrm{CF}$, and reported improved height and weight $\mathrm{Z}$ scores. The first randomized prospective trial was conducted by our group (21) in which we studied 19 prepubertal children (10 received $\mathrm{GH}$ at $0.3 \mathrm{mg} / \mathrm{kg}$ per week). Although no differences existed between the groups at baseline, at 1 year the GH-treated group demonstrated significantly higher height and weight $\mathrm{Z}$ scores and height and weight velocity. Hutler et al. (22) conducted a similar study in Europe and found nearly identical effects on growth (Table 1). Both our group and Hutler evaluated LTM and found it was significantly higher in the treated group (Table 1). Our group recently completed a study of GH used as adjunctive therapy for enteral supplementation (23). We found that GH plus enteral supplementation resulted in greater height and weight gain than enteral

Table 1 This table depicts the anthropometric data from the two published randomized controlled trials of Hutler et al. (22) and Hardin et al. (21) and demonstrates clear evidence that $\mathrm{GH}$ treatment results in improved height, weight and lean tissue mass in prepubertal children with CF. TX, treatment.

\begin{tabular}{ccc}
\hline & $\begin{array}{c}\text { Hardin et al. (21) } \\
\text { 1 year } \\
\text { (19 subjects) }\end{array}$ & $\begin{array}{c}\text { Hutler et al. (22) } \\
\mathbf{6} \text { months } \\
\text { (10 subjects) }\end{array}$ \\
\hline Height & & \\
NonTX & $3.8 \pm 1.2$ & $5.1 \pm 1.1$ \\
GHTX & $8.2 \pm 1.3$ & $9.0 \pm 0.9$ \\
Weight & $2.2 \pm 1.1$ & $1.4 \pm 1.0$ \\
NonTX & $4.2 \pm 1.1$ & $5.0 \pm 0.7$ \\
GHTX & & \\
LBM & $1.8 \pm 1.2$ & $1.8 \pm 1.1$ \\
NonTX & $4.1 \pm 1.1$ & $5.4 \pm 0.9$ \\
GHTX & & \\
\hline
\end{tabular}

Table 2 The data are taken from our randomized trial (21), and our publication on the use of $\mathrm{GH}$ to augment overnight gastrostomy-tube (G-tube) feedings (23). GH provided a significant benefit to patients receiving nutritional supplementation. We also compare the results to our patients who took GH alone. FVC, forced vital capacity; FEV1, forced expiratory volume in $1 \mathrm{~min}$.

\begin{tabular}{lccr}
\hline & G-tube & G-tube+GH & GH only \\
\hline Height velocity (cm/year) & $3.3 \pm 1.1$ & $10.3 \pm 2.03^{*}$ & $8.2 \pm 1.3$ \\
Weight velocity (kg/year) & $3.2 \pm 1.1$ & $9.9 \pm 1.9^{*}$ & $4.2 \pm 1.1$ \\
FVC (change from & $0.05 \pm 0.2$ & $0.43 \pm 0.2^{*}$ & $0.40 \pm 0.3$ \\
baseline in 1 year, l/min) & & & \\
FEV1 (change from & $-5.4 \pm 0.3$ & $+0.34 \pm 0.2^{*}$ & $0.36 \pm 0.2$ \\
baseline in 1 year, l/min) & & &
\end{tabular}

* $P<0.05$ compared to G-tube only group.

supplementation alone (Table 2). In the only study to date of teenagers, we found GH resulted in significant improvement in height, weight and LTM (24).

\section{Clinical status (pulmonary function, hospitalizations and exercise tolerance)}

As previously stated, poor nutritional status is associated with worsened clinical status. One way to assess the clinical status of CF patients is to measure pulmonary function (forced expiratory volume in 1 min (FEV1) and forced vital capacity (FVC)). These can be expressed as absolute values or as percent predicted. Although percent predicted FEV1 is typically used as a surrogate marker for clinical status in people with CF, it is important to realize that the normalization to achieve percent predicted is derived by height matching. For example, a very short child can have relatively poor absolute pulmonary function, but appear to have normal percent predicted values because his/her values are 'matched' to those of a younger, shorter child who has less lung mass. Thus percent predicted pulmonary function is probably not the best surrogate for clinical outcome in a rapidly growing child.

Sackey et al. (17) evaluated FEV1 percent predicted and did not find statistical improvement. Huseman et al. (18) noted a 'trend towards' an increase in absolute FVC, but no change in FVC percent predicted. Alemzadeh et al. (20) were unable to assess pulmonary function secondary to the young age of the children. In our non-randomized trial (19), we found that percent predicted FVC and FEV1 increased during the year of GH treatment in all but two subjects, who remained the same. These results were clinically significant because all of the patients had declining pulmonary function the year prior to study. In our randomized controlled trial (21), we demonstrated improved absolute FVC, but no change in percent predicted FVC. We also found improved peak inspiratory and expiratory pressures, measures used to estimate pulmonary muscle strength. There was no significant change in absolute FVC at 6 months, and neither absolute nor percent predicted FEV1 were significantly different at 
any time point. In our adolescent study (24), we found improvement in both FVC and FEV1 (Fig. 1).

Another way of estimating clinical status is to measure the number of hospitalizations or antibiotic courses. The study by Sackey et al. (17) demonstrated a decrease in the number of courses of antibiotic therapy during $\mathrm{GH}$ compared with pretreatment data. We collected data on intravenous antibiotic use in our first prospective trial (19) and found a decrease with GH. As part of our randomized controlled trial (21), we documented the effect of GH on clinical status by recording the number of hospitalizations and outpatient intravenous antibiotic courses for each subgroup as compared with the year prior to study. The GH-treated group demonstrated significant reduction in both, while there was a slight increase in hospitalizations in the non-treated group. We have found a similar decrease in hospitalizations in our adolescent study (24). Table 3 depicts the data from each study.

Exercise tolerance is yet another way of assessing clinical status. The study by Sackey et al. was the first study to assess this measure. They demonstrated (17) an initial decline in exercise capacity at 6 months, followed by significant improvement over baseline after 12 months of GH treatment. We evaluated (19) muscle strength by kinetic measurements of knee flexion and extension using a Cybex dynamometer in our non-randomized prospective trial. Strength significantly improved with GH; however, when strength was normalized for body weight, there was no difference between baseline and GH-treatment values. These results suggest improved muscle strength was related to body weight, most probably LTM. Hutler et al. (22) evaluated exercise tolerance using cycle ergometry and noted significant improvement in peak power output and $\mathrm{VO}_{\text {peak }}$ by 6 months. The latest group to assess exercise tolerance was Schibler (25). They conducted a trial of 20 patients who varied in age from 10 to 23 years. Subjects were assigned to $\mathrm{GH}$ treatment or no treatment by age and gender matching. Maximal workload and $\mathrm{VO} 2_{\max }$ (both
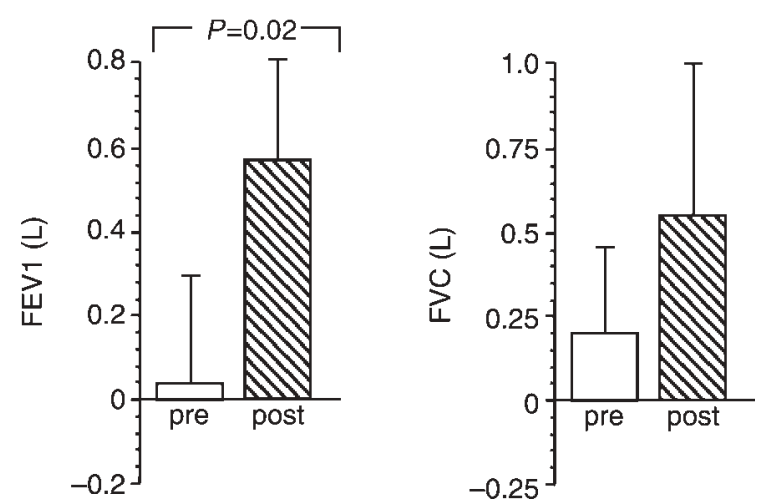

Figure 1 Pulmonary function improvement in GH-treated adolescents.
Table 3 Compiled data on decreased hospitalisation and courses of i.v. antibiotics. Data derived from Sackey et al. (17), Hardin et al. $(19,21,24)$. TX, treatment.

\begin{tabular}{|c|c|c|c|c|c|}
\hline \multirow[b]{2}{*}{ Author } & \multirow{2}{*}{$\begin{array}{l}\text { No. of } \\
\text { subjects } \\
\text { treated } \\
\text { with GH }\end{array}$} & \multicolumn{2}{|c|}{$\begin{array}{c}\text { Decrease in } \\
\text { hospitalizations }\end{array}$} & \multicolumn{2}{|c|}{$\begin{array}{l}\text { Decrease in i.v. } \\
\text { antibiotic use } \\
\text { (occurrences in } \\
12 \text { months) }\end{array}$} \\
\hline & & PreTX & GHTX & PreTX & GHTX \\
\hline Sacke & 7 & \multicolumn{2}{|r|}{ NA } & 13 & $6^{*}$ \\
\hline Hardin et al. (19) & 9 & \multicolumn{2}{|r|}{ NA } & $3.5 \pm 4$ & $1.4 \pm 3^{*}$ \\
\hline Hardin et al. (21) & 10 & $1.8 \pm 1.0$ & $0.9 \pm 0.9^{*}$ & $0.9 \pm 1.7$ & $0.7 \pm 0.8$ \\
\hline Hardin et al. (24) & 19 & $2.1 \pm 0.8$ & $0.69 \pm 0.75^{\star}$ & & $A$ \\
\hline
\end{tabular}

${ }^{\star} P<0.05$ as compared to baseline.

assessed by cardiopulmonary exercise testing unit) significantly increased in the GH-treated group, but did not change in the non-treated group. This study also noted a significant increase in LTM in the treated group.

\section{Other beneficial effects of GH}

\section{Whole-body protein turnover (WBPT)}

Many studies have documented increased WBPT and higher rates of protein breakdown in people with CF. Protein catabolism has been found both in malnourished (26) and non-malnourished groups (27, 28). Our group has found a correlation between negative protein balance and lower growth velocity in CF patients (Fig. 2), as well as in other chronically ill children. Several investigators $(29,30)$ have studied nutritional intervention in CF. Although they document good weight gain, improvement of linear growth is modest. These studies have also found that nutritional augmentation improves protein synthesis, but does not affect protein catabolism. Using oral $\left[{ }^{15} \mathrm{~N}\right]$ glycine, Huseman et al. (18) were the first to evaluate the effect of GH on WBPT in CF. All subjects had a negative nitrogen balance (were protein catabolic) at baseline and all demonstrated improvement after 12 months of GH. Our group utilized the stable isotope of leucine to obtain an estimate of protein breakdown and synthesis (28). When compared with age-matched

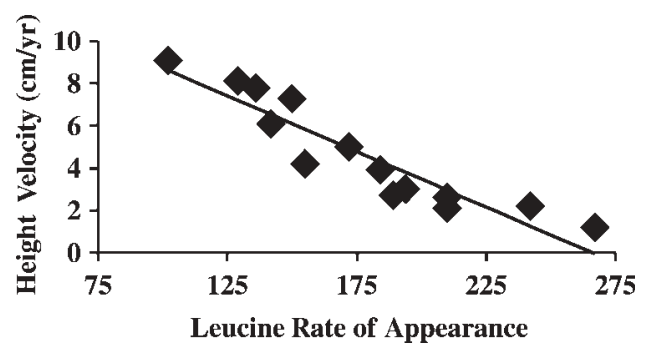

Figure 2 This depicts the association between protein catabolism (leucine rate of appearance) and growth velocity in children with CF participating in our clinical trials. The more catabolic the child, the worse the growth velocity. 
normals, the CF children were protein catabolic. Treatment with GH resulted in significantly lower protein catabolism, suggesting that improvement in weight and LTM was in part due to improved efficiency of whole-body protein kinetics. Interestingly, we did not find improvement in protein synthesis, a finding commonly reported in short-term studies of non-chronically ill GH-deficient children. We have hypothesized that the effects on protein catabolism noted in our CF children were principally secondary to improving their clinical status and to improvement in insulinlike growth factor-I (IGF-I) levels. Improvement of growth by improving IGF-I levels has been demonstrated in other types of chronic illness $(13,14,31)$ and in protein-calorie malnutrition). Low IGF-I levels $(28,32)$ and high levels of cytokine tumor necrosis factor- $\alpha$ (TNF)- $\alpha$ (33) have been reported in both adults and children with CF. Our group has documented (28) significant increase in IGF-I levels, as well as decreased levels of TNF- $\alpha$, with GH treatment.

Osteoporosis is common in CF, occurring in an estimated $33 \%$ of adults and $8-20 \%$ of children with CF (34). The pathophysiology of osteoporosis is both excessive stimulation of osteoclasts (possibly from cytokines) (35), as well as decreased osteoblast function. GH increases osteoblast activity and long-term study of $\mathrm{GH}$ in GH-deficient adults has demonstrated improvement in bone density with GH (36). Schnable et al. (37) studied bone metabolism in 12 children using markers of bone formation and breakdown, as well as measuring bone density by quantitative catscan. They found bone density to be normal in these prepubertal patients, but also noted an increase in total bone density in 8 of the 12 children treated with GH. There was no change in the non-treated children. Our group recently completed an evaluation of $\mathrm{GH}$ effects on bone in children with $\mathrm{CF}$ and found significantly better accrual of bone mineral in GH-treated children (Fig. 3).

Although glucose intolerance is a significant problem in patients with CF (38), to date glucose intolerance has been documented in only one published study of GH in CF. In this retrospective study (16), the two patients who demonstrated glucose intolerance were pubertal and no prescreening for diabetes was indicated. Glucose

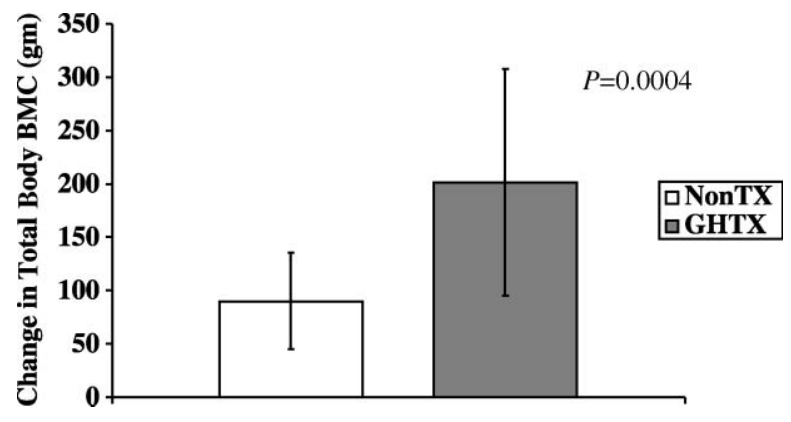

Figure 3 Increased bone accrual in GH-treated prepubertal children. $\mathrm{BMC}$, bone mineral content. intolerance occurs most often in adults and pubertal patients (38); therefore, these two patients may have already had the problem prior to the initiation of GH. No other study has documented glucose intolerance or any other side effect of GH.

\section{Summary}

All published studies of GH use in children with CF have demonstrated significant improvement in height velocity and height $\mathrm{Z}$ score. All studies but one, in which subjects were treated only three times per week with $\mathrm{GH}$, have demonstrated improvement in weight as reported by weight velocity and/or weight $\mathrm{Z}$ score, and one trial has demonstrated a substantial improvement when GH was used to augment nutritional therapy. Several reports suggest that GH treatment results in clinical improvement of $\mathrm{FVC}$; however, this may simply be a result of improved longitudinal growth. Multiple studies have found improved clinical status as measured by decreased hospitalizations and courses of intravenous antibiotics, and thus far evidence also suggests that GH results in improvement in exercise tolerance and bone accumulation. Thus mounting evidence suggests that human recombinant GH provides safe and effective therapy in children with CF. Our group is currently conducting a large randomized prospective trial which should help identify which children (poorly growing or moderately growing) with CF would benefit most from the drug. This very large study will also help to improve our understanding of whether $\mathrm{GH}$ results in better pulmonary function, beyond the effect of growth.

\section{References}

1 Cystic Fibrosis Foundation. Cystic fibrosis foundation patient registry annual data report, pp 1-27. Cystic Fibrosis Foundation, Bethesda, MD, 2000.

2 Byard P. The adolescent growth spurt in children with cystic fibrosis. Annals of Human Biology 199421 229-240.

3 Johannesson M, Carlson ME, Bergsten Brucefors A \& Hjelte L. Cystic fibrosis through a female perspective: psychosocial issues and information concerning puberty and motherhood. Patient Education and Counseling 199834 115-123.

4 Cystic Fibrosis Foundation. Nutritional Assessment and Management In Cystic Fibrosis, Consensus Conferences. Cystic Fibrosis Foundation, Bethesda, MD, 1990.

5 Kraemer R, Rudeberg A, Hadorn B \& Rossi E. Relative underweight in cystic fibrosis and its prognostic value. Acta Paediatrica Scandanavica $19786733-35$.

6 Konstan MW, Butler SM, Wohl ME, Stoddard M, Matousek R, Johnson CA, Wagener JS \& Morgan WJ. Growth and nutritional indexes in early life predict pulmonary function in cystic fibrosis. Journal of Pediatrics 142 624-630.

7 Becker LT, Russek-Cohen E \& Fink RJ. Stature as a prognostic factor in cystic fibrosis survival. Journal of the American Dietetic Association $2003101438-442$.

8 Byard PJ. Early Childhood growth in patients with cystic fibrosis. Annals of Human Biology 199017 483-499. 
9 Corey M, McLaughlin FJ, Williams M \& Levison H. A comparison of survival, growth, and pulmonary function in patients with cystic fibrosis in Boston and Toronto. Journal of Clinical Epidemiology 198841 583-591.

10 Lai HC, Corey M, FitzSimmons S, Kosorok MR \& Farrell PM. Comparison of growth status of patients with cystic fibrosis between the United States and Canada. American Journal of Clinical Nutrition $199969531-538$.

11 Hardin DS. Growth problems and growth hormone treatment in children with cystic fibrosis. Journal of Pediatric Endocrinology and Metabolism $200215731-735$.

12 Bechtold S, Ripperger D, Muhlbayer H, Truckenbrodt R, Hafner O, Butenandt O \& Schwartz HP. GH therapy in juvenile chronic arthritis: results of a two-year controlled study on growth and bone. Journal of Clinical Endocrinology and Metabolism 200286 5737-5744

13 Byrne TA, Morrissey TB, Gatzen C, Benfell K, Nattakom TV, Schettinga MR, LeBoff MS, Ziegler TR \& Wilmore DW. Anabolic therapy with growth hormone accelerates protein gain in surgical patients requiring nutritional rehabilitation. Annals of Surgery $1993218400-418$

14 Koch VH, Lippe BM, Sherman BM \& Fine RN. Accelerated growth following recombinant human growth hormone therapy in children with chronic renal failure. Pediatric Research 198823 541A.

15 Hubbard VS, Davis PB, di Sant'Agnese PA, Gorden P \& Schwartz RH. Isolated growth hormone deficiency and cystic fibrosis: a report of two cases. American Journal of Diseases in Children 1980134 317-319.

16 Hardin DS \& Sy JP. Effects of growth hormone treatment in children with cystic fibrosis: The National Cooperative Growth Study experience. Journal of Pediatrics 1997131 S65-S68.

17 Sackey AH, Taylor CJ, Barraclough M, Wales JKH \& Pickering M. Growth hormone as a nutritional adjunct in cystic fibrosis: results of a pilot study. Journal of Human Nutrition and Dietetics $1995 \mathbf{8}$ 185-191.

18 Huseman CA, Colombo JL, Brooks MA, Smay JR, Greger NG, Sammut PH \& Bier DM. Anabolic effect of biosynthetic growth hormone in cystic fibrosis patients. Pediatric Pulmonology 1996 22 90-95.

19 Hardin DS, Stratton R, Kramer JC, Reyes de la Rocha S, Govaerts K \& Wilson DP. Growth homone improves weight velocity and height velocity in children with cystic fibrosis. Hormone and Metabolic Research 199830 636-641.

20 Alemzadeh R, Upchurch L \& McCarthy V. Anabolic effects of growth hormone treatment in young children with cystic fibrosis. Journal of the American College of Nutrition $200117419-424$.

21 Hardin DS, Ellis K, Dyson M, McConnel R, Rice J \& Seilheimer DK. Growth hormone improves clinical status in children with cystic fibrosis - results of a randomized controlled trial. Journal of Pediatrics $2001139636-642$.

22 Hutler M, Schnabel D, Staab D, Tacke A, Wahn U, Boning D \& Beneke R. Effect of growth hormone on exercise tolerance in children with cystic fibrosis. Medicine in Science and Sports and Exercise $200225567-572$.

23 Hardin DS, Rice J, Ahn C, Ferkol T, Howenstine M, Spears S, Prestidge C, Seilheimer DK \& Shepherd R. Growth hormone treatment enhances nutrition and growth in children with cystic fibrosis receiving enteral nutrition. Journal of Pediatrics (In Press).
24 Hardin DS, Ferkol T, Ahn C, Dreimane D, Dyson M, Morse M, Prestidge C, Rice J \& Seilheimer DK. Growth hormone improves height and weight in adolescents with cystic fibrosis. Pediatric Pulmonology 200224337.

25 Schibler A. Prospective randomized treatment with recombinant human growth hormone in cystic fibrosis. Archives of Disease in Childhood $2003 \mathbf{8 8} 1078-1081$.

26 Miller M, Ward L, Thomas BJ, Cooksley WGE \& Shepherd RW. Altered body composition and muscle protein degradation in nutritionally growth-retarded children with cystic fibrosis. American Journal of Clinical Nutrition $198236492-499$.

27 Dalzell AM, Shepherd RW, Dean B, Cleghorn GJ, Holt TL \& Francis PJ. Nutritional rehabilitation in cystic fibrosis: a 5 year follow-up study. Journal of Pediatric Gastroenterology and Nutrition 199215 $141-145$.

28 Hardin DS, Dyson M, Rice J, Seilheimer DK \& Ellis KJ. Growth hormone improves protein catabolism in children with cystic fibrosis. Journal of Clinical Endocrinology and Metabolism $2001 \mathbf{8 5}$ $4424-4428$.

29 Erkine JM, Lingard SD, Sontag MK \& Accurso FJ. Enteral nutrition for patients with cystic fibrosis: comparison of a semi-elemental and nonelemental formula. Journal of Pediatrics $1998 \mathbf{1 3 2}$ 265-269.

30 Holt TL, Ward LC, Francis PJ, Isles A, Cooksley WGE \& Shepherd RW. Whole body protein turnover in malnourished cystic fibrosis patients and its relationship to pulmonary disease. American Journal of Clinical Nutrition 198541 1061-1066.

31 White PH. Growth disturbances in children with juvenile rheumatoid arthritis. Clinical Orthopaedics and Related Research 1990 $25946-50$.

32 Green OC, Fefferman R \& Nair S. Plasma growth hormone levels in children with cystic fibrosis and short stature. Unresponsiveness to hypoglycemia. Journal of Clinical Endocrinology and Metabolism 196727 1059-1061.

33 Wilmott RW, Frenzke M, Kociela V \& Peng L. Plasma Interleukin-I alpha and beta, tumor necrosis factor-alpha, and lipopolysaccharide concentrations during pulmonary exacerbations of cystic fibrosis. Pediatric Pulmonology 199418 21-27.

34 Aris RM. Osteoporosis in CF - A review of therapies. Drugs 2004 64 133-147.

35 Teramoto S, Matsuse T \& Ouchi Y. Increased production of TNFalpha may play a role in osteoporosis in cystic fibrosis patients. Chest 1997122 574-575.

36 Cooper C \& Melton LJ. Osteopenia in childhood and adolescence. In Osteoporosis, pp 785-799. Eds R Marcus, D Feldman \& J Kelsey. San Diego: Academic Press, 1996.

37 Schnabel D, Schonau E, Staab D, Tacke A, Felsenberg D, Wahn U \& Gritters A. Effects of growth hormone therapy on bone metabolism in patients with cystic fibrosis (CF). In Pediatric Osteology: Prevention of Osteoporosis - a Pediatric Task? pp 209-217. Eds E Schonau \& V Matkovic. Singapore: Elsevier Science, 1998.

38 Hardin DS. Cystic fibrosis related diabetes. Endocrinologist $1998 \mathbf{8}$ 265-272.

Received 9 February 2004

Accepted 19 April 2004 